\title{
Effect of Pulsating Flow on Mass Transfer in Packed Bed under $\mathrm{Fe}^{3+}$-iron Particle System
}

\author{
Tateo USUI, Hirotoshi KAWABATA, Shigeo MATSUBARA, ${ }^{1)}$ Hiroshi FUKASAKU, ${ }^{2)}$ Takeshi \\ MIZUTANI ${ }^{3)}$ and Zen-ichiro MORITA
}

Department of Materials Science and Processing, Faculty of Engineering, Osaka University, Yamadaoka, Suita, Osaka-fu, 565 Japan. $\quad 1)$ Formerly Steel R \& D Laboratories. Now at Plastic Working Laboratories, Nisshin Steel Co., Ltd., Tsurumachi, Amagasaki, Hyogo-ken, 660 Japan. $\quad 2$ 2) Formerly Faculty of Engineering, Osaka University. Now at Toyoda Automatic Loom Works, Ltd., Toyodacho, Kariya, Aichi-ken, 448 Japan. $\quad 3$ ) Formerly Faculty of Engineering, Osaka University. Now at Nakayama Steel Works, Ltd., Funamachi, Taishou-ku, Osaka, Osaka-fu, 551 Japan.

(Received on July 1. 1993; accepted in final form on September 24, 1993)

\begin{abstract}
Effect of pulsating flow on mass transfer in packed bed is studied by taking $\mathrm{Fe}^{3+}$-iron particle system as an example of liquid-solid system, because of the industrial requirement of iron plating. Spherical and cubic particles are used as packing materials having very different shapes. Pulsation is generated by a rotary cock or a piston.

Mass transfer coefficient $k_{L}$ for cube-packed bed under steady flow is larger than that for sphere one. Comparison of $k_{L}$ under steady and pulsating flow without reverse flow (by rotary cock) shows no effect of pulsating flow on mass transfer for both sphere- and cube-packed bed. In comparison with $k_{L}$ under steady and pulsating flow with reverse flow (by piston), however, remarkable difference reveals. That is, mass transfer for sphere-packed bed is accelerated under quasi-steady state and that for cube-packed bed is promoted much more than in quasi-steady state, where mass transfer is assumed to proceed depending on the absolute value of velocity.

Velocity fluctuations just after the bed are measured by a hot film probe and the difference between the flow fields for sphere- and cube-packed bed is discussed in connection with the difference of the mass transfer under steady and pulsating flow.
\end{abstract}

KEY WORDS: mass transfer; liquid-solid reaction; pulsating flow; steady flow; packed bed; sphere; cube; iron plating.

\section{Introduction}

As to treatment of plating solutions such as acceleration of $\mathrm{Fe}^{3+}$-ion reduction in iron plating solutions, which is industrially important, adoption of higher temperatures and higher flow rates together with that of smaller iron-particle diameters for increasing reaction surface area have been tried. In the present work the accelerating effect of pulsation applied to liquid flow upon the reaction is investigated.

In gas-solid and liquid-solid reactions where mass transfer is rate-controlling especially, pulsation effect has been known so far by Ohmi et al.'s ${ }^{1)}$ and Kitaura et al.' $\mathrm{s}^{2)}$ reports; when the liquid flow contacts with and passes through solids under pulsating flow, mass transfer between fluid and solids is accelerated and the overall reaction rate is improved in comparison with that under steady flow. Most of these studies, however, concern mass transfers from a single particle ${ }^{1,3-8)}$ or the inside walls of tubes. ${ }^{9,10)}$ There are a few reports ${ }^{2,11,12)}$ regarding packed beds important from a practical point of view. It is also to be noted that many reports ${ }^{2,11,12)}$ performed experiments by using inert spheres. In particular, few reports exist which described the packed beds of liquidsolid systems important for the treatment of plating solutions. Particles used for the experiments, moreover, were mostly spherical and cylindrical, and a few experiments used particles other than round shapes.

In the present work, iron plating solution, i.e. $\mathrm{Fe}^{3+}$ ion-Fe particle systems ${ }^{13,14)}$ were taken up as an example of a liquid-solid reaction in packed beds from the points mentioned above, and the mass transfer coefficients for steady and pulsating flow in particle-packed beds were measured using spherical and cubic particles as extremely different-shape particles. Thereby the influence of different particle shapes on mass transfer was evaluated and reaction-accelerating effect due to the addition of pulsating flow was investigated.

\section{Analysis of Mass Transfer Rates}

In reduction treatment of $\mathrm{Fe}^{3+}$ ion using metalic iron, because the reduction reaction from $\mathrm{Fe}^{3+}$ ions to $\mathrm{Fe}^{2+}$ ions is very fast, the diffusion of $\mathrm{Fe}^{3+}$ ions to the surface of the iron particles is regarded as the rate-controlling step. ${ }^{13)}$ Since there is no adequate example of analysis 
regarding the reduction characteristics under pulsating flow in a packed bed, a simplified model applicable to both steady and pulsating flows will be proposed in this section. In Fig. 1, the mass balance in the bed packed with iron particles can be expressed as

$$
C_{b, \text { in }} \cdot Q=-N^{\prime}+C_{b, \text { out }} \cdot Q \text {, }
$$

where, $C_{b \text {,in }}: \mathrm{Fe}^{3+}$ ion concentration at the inlet of packed bed $\left(\mathrm{kg} / \mathrm{m}^{3}\right)$

$C_{b, \text { out }}: \mathrm{Fe}^{3+}$ ion concentration at the outlet of packed bed $\left(\mathrm{kg} / \mathrm{m}^{3}\right)$

$N^{\prime}$ : amount of change in $\mathrm{Fe}^{3+}$ ions in packed bed per unit time $(\mathrm{kg} / \mathrm{s})\left(N^{\prime}<0\right)$

$Q$ : flow rate of experimental solution $\left(\mathrm{m}^{3} / \mathrm{s}\right)$.

On the other hand, since the diffusion is the ratecontrolling step in the following reaction:

$$
\mathrm{Fe}^{3+}+\mathrm{e}^{-} \rightarrow \mathrm{Fe}^{2+},
$$

$N^{\prime}$ can be written as follows:

$$
N^{\prime}=A \cdot N_{A}=-A \cdot k_{L} \cdot\left(C_{b}-C_{o}\right),
$$

where, $A$ : total surface area of iron particles in packed bed $\left(\mathrm{m}^{2}\right)$

$C_{b}: \mathrm{Fe}^{3+}$ ion concentration in bulk solution $\left(\mathrm{kg} / \mathrm{m}^{3}\right)$

$C_{0}: \mathrm{Fe}^{3+}$ ion concentration at the surface of an iron particle $\left(\mathrm{kg} / \mathrm{m}^{3}\right)$

$k_{L}$ : mass transfer coefficient $(\mathrm{m} / \mathrm{s})$

$N_{A}$ : amount of $\mathrm{Fe}^{3+}$ ions transferred per unit area and unit time at liquid-solid interface $\left(\mathrm{kg} /\left(\mathrm{m}^{2} \cdot \mathrm{s}\right)\right)$

The difference between $\mathrm{Fe}^{3+}$ ion concentrations at the inlet and outlet of the packed bed $\left(C_{b, \text { in }}-C_{b, \text { out }}\right)$ is relatively small in the present packed bed length and the present ranges of $\mathrm{Fe}^{3+}$ ion concentration. Therefore, the concentration distribution in the packed bed can be assumed to be approximately linear. This was verified experimentally (see Fig. 3), and hence we obtain

$$
C_{b}=\left(C_{b, \text { in }}+C_{b, \text { out }}\right) / 2 \text {. }
$$

Further, because the reaction between iron particles and $\mathrm{Fe}^{3+}$ ions is very fast, the relation $C_{0}=0$ is assumed and Eq. (2) can be rewritten as follows:

$$
N^{\prime}=-A \cdot k_{L} \cdot\left(C_{b, \text { in }}+C_{b, \text { out }}\right) / 2 .
$$

Therefore, substitution of Eq. (4) into Eq. (1) gives

$$
Q\left(C_{b, \text { in }}-C_{b, \text { out }}\right)=A \cdot k_{L} \cdot\left(C_{b, \text { in }}+C_{b, \text { out }}\right) / 2 \text {. }
$$

Mass transfer coefficient $k_{L}$ can then be calculated by measuring $A, C_{b, \text { in }}, C_{b, \text { out }}$ and $Q$.

\section{Experiments}

\subsection{Experimental Apparatuses}

The horizontal and vertical packed bed apparatuses used in experiments are shown in Figs. 2(a) and 2(b), respectively. The portions in direct contact with experimental solution are made of vinyl chloride and acrylic resin or metals covered with Teflon. The test sections of both packed beds are made of an acryl pipe of $40 \mathrm{~mm}$ I.D. and $590 \mathrm{~mm}$ length. The experimental

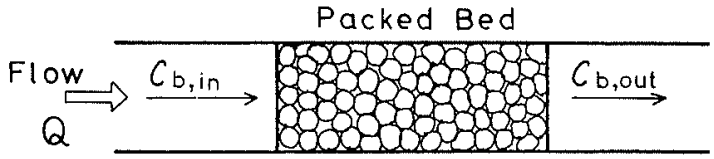

Fig. 1. Mass balance model in a bed packed with iron particles.

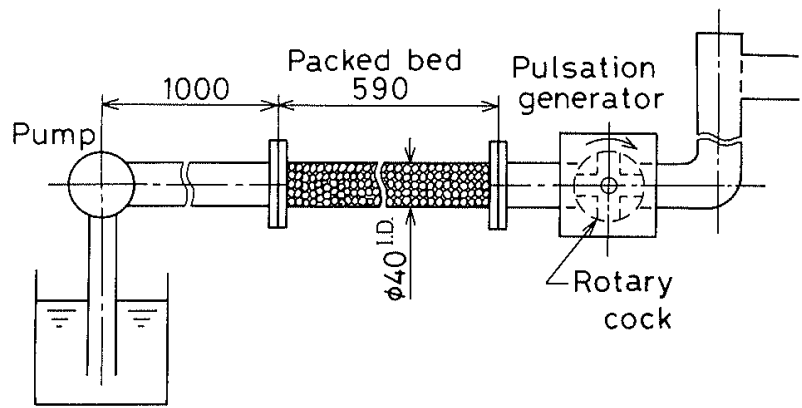

(a) Horizontal packed bed type (Rotary cock type)

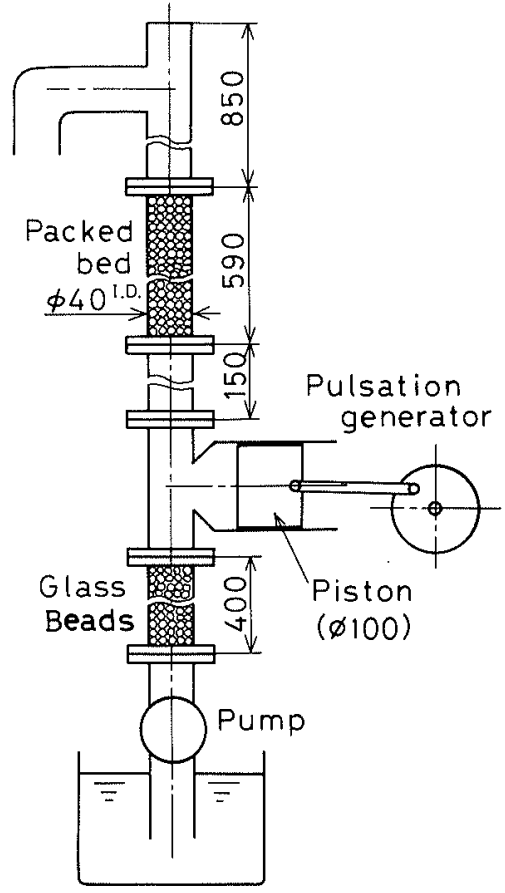

(b) Vertical packed bed type (Piston type)

Fig. 2. Schematic layout of the experimental apparatuses; dimensions in $\mathrm{mm}$.

solution was pumped into the bed packed with iron particles. The flow rate was changed by adjusting the pump output. Moreover, temperature of the experimental solution was kept constant at $293 \mathrm{~K}$ to eliminate the temperature dependency.

Figure 2(a) shows a horizontal packed bed apparatus. Pulsating flow was generated by a rotary cock (highfrequency, low-amplitude) without reverse flow. The pulsation frequency was adjusted by changing the number of revolution of the motor.

Figure 2(b) shows a vertical packed bed apparatus, 
and pulsating flow was generated by a piston $(100 \mathrm{~mm}$ in diamter, low-frequency, high-amplitude) with reverse flow. Glass beads were filled in front of the test section to depress the backward propagation of pulsation and to settle the flow. The pulsation frequency was adjusted by changing the number of revolution of the motor, whereas the pulsation amplitude was changed by shifting the axis of rotation of the piston-crank.

Superficial liquid velocity $u_{m}$ (steady flow) and timeaveraged superficial liquid velocity $u_{m, \text { ta }}$ (pulsating flow) were calculated by measuring the flow rates at the exit. The pulsating velocity amplitude $a \omega$ without reverse flow was measured by using a hot-film anemometer under a water model, while the amplitude of liquid with reverse flow was obtained by measuring the difference between the upper and the lower liquid levels of the free surface. After measuring Oxidation-Reduction Potential (ORP), the concentration ratio of $\mathrm{Fe}^{3+}$ to $\mathrm{Fe}^{2+}$ was evaluated from a relation between $\mathrm{Fe}^{3+} / \mathrm{Fe}^{2+}$ and ORP presented experimentally by Matsubara et al. ${ }^{14)}$

\subsection{Experimental Solution and Iron Particles}

The experimental solution to be used in a series of reduction experiments was prepared by electrolytic oxidation of $\mathrm{Fe}^{2+}$ ions existing in the aqueous solution of ferrous chloride $\left(\mathrm{FeCl}_{2}\right)$. The total $\mathrm{Fe}$ ion concentrations, $\mathrm{Fe}^{3+} / \mathrm{Fe}^{2+}$ concentration ratios and $\mathrm{pH}$ were in the range of 217 to $230 \mathrm{~kg} / \mathrm{m}^{3}, 0.05$ to 0.2 and 0.3 to 1.0 , respectively.

Two kinds of iron particles, namely, the spherical and cubic ones were used. Bearing balls with diameter $d_{p}=$ $4.83 \mathrm{~mm}$ were used as spherical particles. As cubic particles a low-carbon rolled steel sheet was used after cutting to form a cubes with a volume of $48.2 \mathrm{~mm}^{3}$ and a side length of about $3.6 \mathrm{~mm}$, the volume equivalent diameter $d_{p}^{*}$ of which was about $4.5 \mathrm{~mm}$. The main chemical components of the spherical particles were 99.0 mass $\% \mathrm{Fe}$ or more, 0.65 mass $\% \mathrm{C}$ and 0.25 mass $\%$ $\mathrm{Mn}$, whereas those of the cubic particles were 99.6 mass $\%$ $\mathrm{Fe}, 0.03$ mass $\% \mathrm{C}$ and 0.27 mass $\% \mathrm{Mn}$. In packed beds, the void fractions of the cubic particles and spherical ones were 0.37 and 0.39 , respectively. It is to be noted that iron particles were filled little by little in air by vibrating the packed bed.

\section{Results and Discussion}

\subsection{Distribution of $\mathrm{Fe}^{3+}$ Concentrations in Packed Beds}

The packed bed length provided for the steady and pulsating flow experiments was $590 \mathrm{~mm}$. Thereupon, the bed, $750 \mathrm{~mm}$ in length, packed with the cubic particles was used to measure $\mathrm{Fe}^{3+}$ concentration profiles from the inlet to the outlet under steady flow at intervals of $150 \mathrm{~mm}$. The results are shown in Fig. 3, which indicates that each gradient of $\mathrm{Fe}^{3+}$ concentration in the packed bed is nearly constant at each superficial liquid velocity $u_{m}$, regardless of the variation of $u_{m}$. Therefore, the assumption of Eq. (3) is valid.

\subsection{Mass Transfer Coefficients under Steady Flow}

\subsubsection{In the Case of Horizontal Packed Beds}

Figure 4 gives the relations between mass transfer

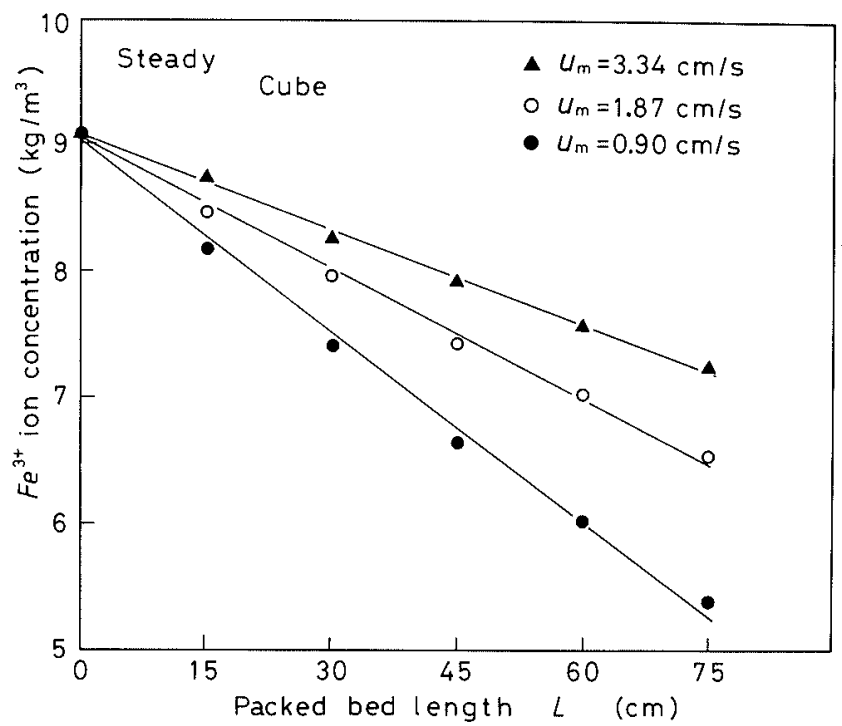

Fig. 3. Variation of $\mathrm{Fe}^{3+}$-ion concentration with packed bed length.

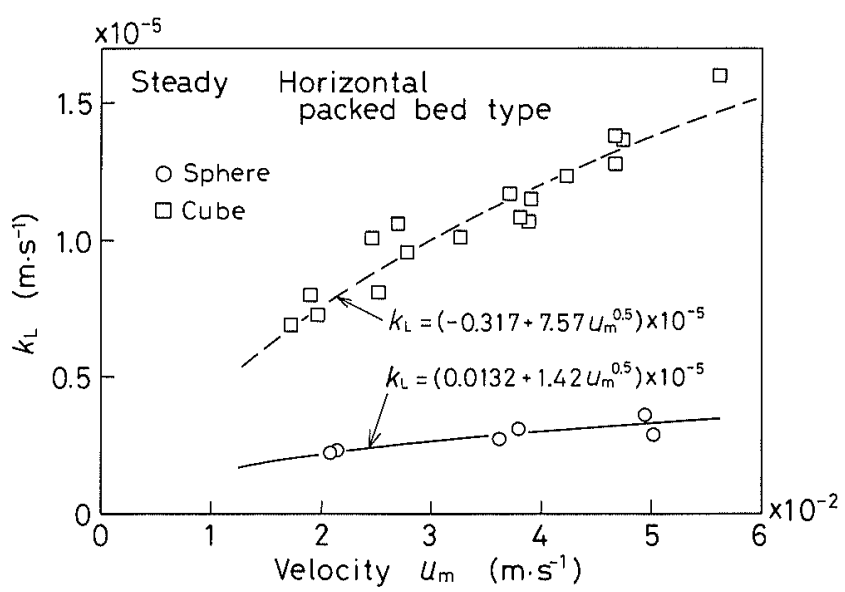

Fig. 4. Variation of mass transfer coefficient $k_{L}$ with superficial liquid velocity based on empty column $u_{m}$ in steady flow (horizontal packed bed)

coefficient $k_{L}$ and superficial liquid velocity $u_{m}$ for the spherical and cubic particles under steady flow in the horizontal packed bed (Reynolds number; $R e=u_{m}$. $d / v=35-100$ ). The solid and broken curves in Fig. 4 are drawn by applying the least square method, and can be written within the present experimental range as follows:

$$
\begin{aligned}
& k_{L}=\left(0.0132+1.42 u_{m}^{0.5}\right) \times 10^{-5}(\mathrm{~m} / \mathrm{s}) \quad \text { (for sphere) } \\
& k_{L}=\left(-0.317+7.57 u_{m}^{0.5}\right) \times 10^{-5}(\mathrm{~m} / \mathrm{s}) \quad \text { (for cube) }
\end{aligned}
$$

Mass transfer for both particles is enhanced with the increase in flow velocity $u_{m}$, and the mass transfer coefficients for cubes are much greater than those for spheres.

\subsubsection{In the Case of Vertical Packed Beds}

Figure 5 depicts the experimental results for the spheres and cubes under steady flow in the case of the vertical packed bed $\left(R e=u_{m} \cdot d / v=15-100\right)$. The solid and broken curves are drawn by applying the least square method, 


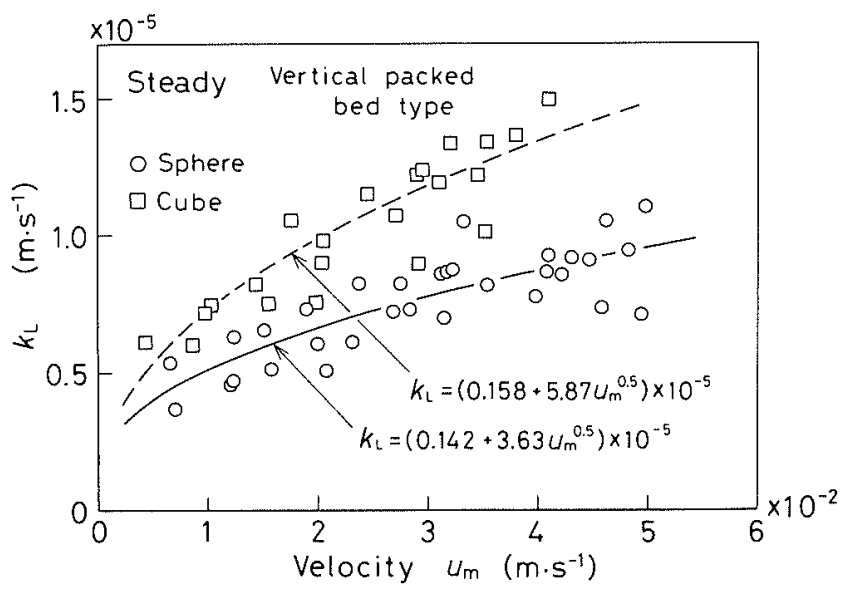

Fig. 5. Variation of mass transfer coefficient $k_{L}$ with superficial liquid velocity based on empty column $u_{m}$ in steady flow (vertical packed bed).

and can be written within the present experimental range as follows:

$k_{L}=\left(0.142+3.63 u_{m}^{0.5}\right) \times 10^{-5}(\mathrm{~m} / \mathrm{s}) \quad$ (for sphere)

$k_{L}=\left(0.158+5.87 u_{m}^{0.5}\right) \times 10^{-5}(\mathrm{~m} / \mathrm{s}) \quad$ (for cube) .

In this case, the mass transfer coefficients for cubes are also greater than those for spheres. This is considered to be because different packed forms due to different shapes of particles lead to the different states of flow within the packed beds. This will be discussed in detail in Sec. 4.5.

\subsubsection{Difference between Mass Transfer Coefficients for Horizontal and Vertical Packed Beds}

It is understood from comparison between Figs. 4 and 5 that the mass transfer coefficients for the horizontal bed packed with spheres differ greatly from those for the vertical one but the difference in the case of cubes is not so large as that in the case of spheres. This is considered to be caused by the differences between packing states and between flow patterns in the beds packed with spheres and cubes; that is, the state of packing for spheres is relatively regular, and when the packed bed is set horizontally, a very slight gap is formed more along the upper part of the tube wall as compared with the cube-packed bed. In addition, the relatively regular state of the sphere-packed bed results in fewer zigzag flow paths (channeling phenomenon) as compared with the cube-packed bed. On the other hand, the difference of packing states between the horizontal packed bed and the vertical one is smaller in the case of cube-packed bed. Moreover, by using angular particles like cubes, the mass transfer coefficient is hardly affected by a very slight gap at the upper part of the tube wall in the horizontal bed packed with cubes, because the zigzag flow paths are great many. This way of thinking is supported by the results of velocity fluctuation measurement that will be described in the subsequent section. Accordingly, mixing and stirring of the liquid in the horizontal bed packed with spheres are insufficient, and thereby the liquid tends to pass through the gaps along the tube wall. For this reason, the mass transfer coefficients for the horizontal bed packed with spheres are considered to be fairly
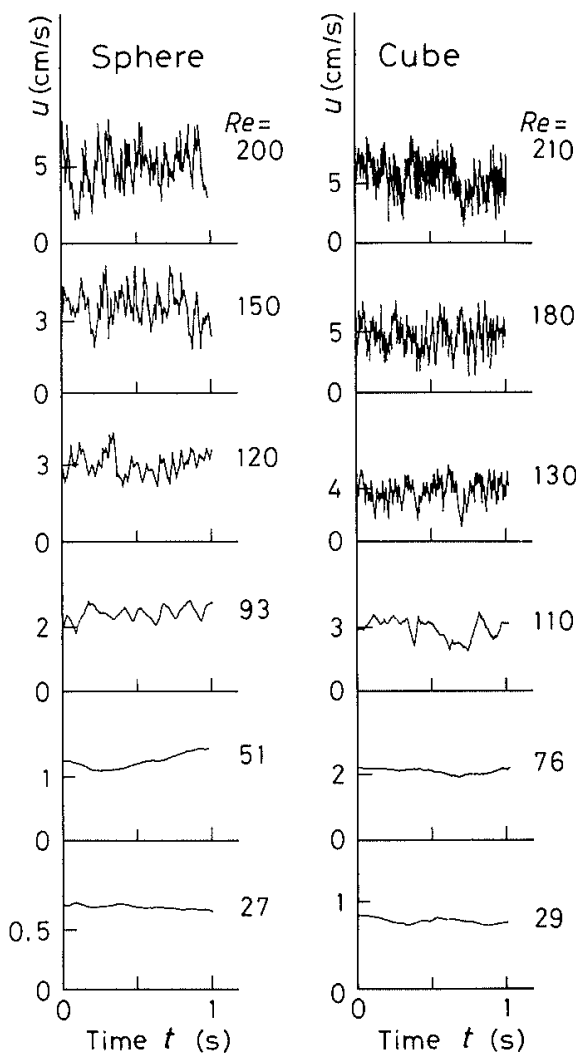

Fig. 6. Velocity fluctuation behind the packed bed in the case of water model.

small.

For the mass transfer coefficient under steady flow, therefore, adoption of Eqs. (8) and (9) for the vertical packed bed is considered to be adequate.

\subsection{Measurement of Velocity Fluctuation behind the Packed Bed under Steady Flow}

To infer the state of flow in the packed beds, the flows immediately after the sphere- and the cube-packed beds were measured by using the hot-film anemometer under the water model. In the flow measurement experiments, about $0.6 \mathrm{~kg}$ iron particles were packed (about $100 \mathrm{~mm}$ packed bed length), the hot-film probe was then set at about $2 \mathrm{~mm}$ apart from the outlet of packed bed at the centerline of tube, and flow measurements were made at various velocities under steady flow. The results are shown in Fig. 6. To avoid the superposition of velocity waveforms, zero points are shifted. The hot-film probe used in this experiment can not detect the flow directions. From Fig. 6, the fluctuation of flow becomes more violent as Reynolds number $\left(u_{m} \cdot d / v\right)$ increases. Since the scale of this fluctuation is in the same order as that of the mean velocity, the fluctuation is considered not to arise from the wake of particles, but from the channeling of the flow.

It is well known that packed beds are often used for settling flows. In this measurement, the fluctuation of flow could hardly be detected when the hot-film probe was set at the center of the tube about $20 \mathrm{~mm}$ apart from the packed bed. When the probe was brought close gradually to the packed bed, fiuctuation began to be detected at the position about $10 \mathrm{~mm}$ apart from the bed and became 
violent in the range $2-3 \mathrm{~mm}$ from the bed. Ranz ${ }^{15}$ ) considered that the axial velocity in the packed bed was about ten times as much as the superficial velocity. It is inferred from the Ranz's opinion and the results of the above-mentioned measurements that within the packed bed more violent channeling of flow may occur, and the velocity $u$ of the liquid flowing through the gaps of particles may reach instantaneously serveral ten times as much as superficial liquid velocity. Therefore the mixing and stirring of the liquid in the packed bed are considered to be active. In these experiments, no disturbance due to the wake of particles was measured. In a single sphere, however, the Reynolds number at which wake begins to occur is in the order of $R e=u \cdot d / v=200$, whereas in a single cube the Reynolds number at which wake begins to occur may be smaller than the above value because of its angular shape. As mentioned above, since violent channeling phenomena take place and flow velocity $u$ is extremely large in the packed bed, Reynolds number $(u \cdot d / v)$ in it becomes extremely high, and disturbance due to wake may occur.

\subsection{Mass Transfer Coefficients under Pulsating Flow}

4.4.1. In the case of Pulsating Flow without Reverse Flow $\left(a \omega / u_{m, \mathrm{ta}}<1\right)$

Under the pulsating flow without reverse flow by using the apparatus shown in Fig. 2(a), frequency $f$ is $12-20 \mathrm{~Hz}$ and velocity amplitude ratio $a \omega / u_{m, t a}$ is $0.15-0.27$. If the flow in the tube is of piston flow type, then calculation based on velocity amplitude aw leads to amplitude $a=0.04-0.14 \mathrm{~mm}$. When the superficial liquid velocity of pulsating flow $u_{m, \mathrm{pl}}$ varies in the form of a sine curve having time-averaged superficial liquid velocity $u_{m, \text { ta }}$ and amplitude $a \omega$ (see Eq. (12)), $a \omega / u_{m \text {,ta }}$ is called velocity amplitude ratio. If $a \omega / u_{m, \text { ta }}>1$, then reverse flow occurs. The velocity amplitude ratio of pulsation was measured before and after the position of the packed bed by using the hot-film anemometer under the water model. Waveforms are exemplified in Fig. 7. Under the present experimental conditions, the velocity amplitude ratio is relatively small, and no reverse flow occurs. Before and after the mass transfer experiments under pulsating flow, those under steady flow were also carried out by using the experimental solution with the same concentration for the purpose of comparison.

Figure 8 shows the experimental results of mass transfer coefficient $k_{L}$ as a function of time-averaged superficial liquid velocity $u_{m, \mathrm{ta}}$. Figure 8 also depicts the approximate curves obtained from steady flow experiments. In the range of low velocities, the approximate curve for the sphere-packed bed is lengthened and the resultant curve is drawn by a dotted line. In both spherical and cubic particles, there is no difference between the experimental results of steady and pulsating flows, and accordingly no effect of pulsation is observed within the range of these experiments where no reverse flow is found.

So far, Ohmi et al. ${ }^{1,8)}$ and Kitaura et $a l^{2)}$ revealed that when a single sphere was placed in fluid flow and the pulsation frequency $f$ became large the mass transfer was accelerated; that is, vortex by the wake and secondary flow occurred and then velocity gradient became greater
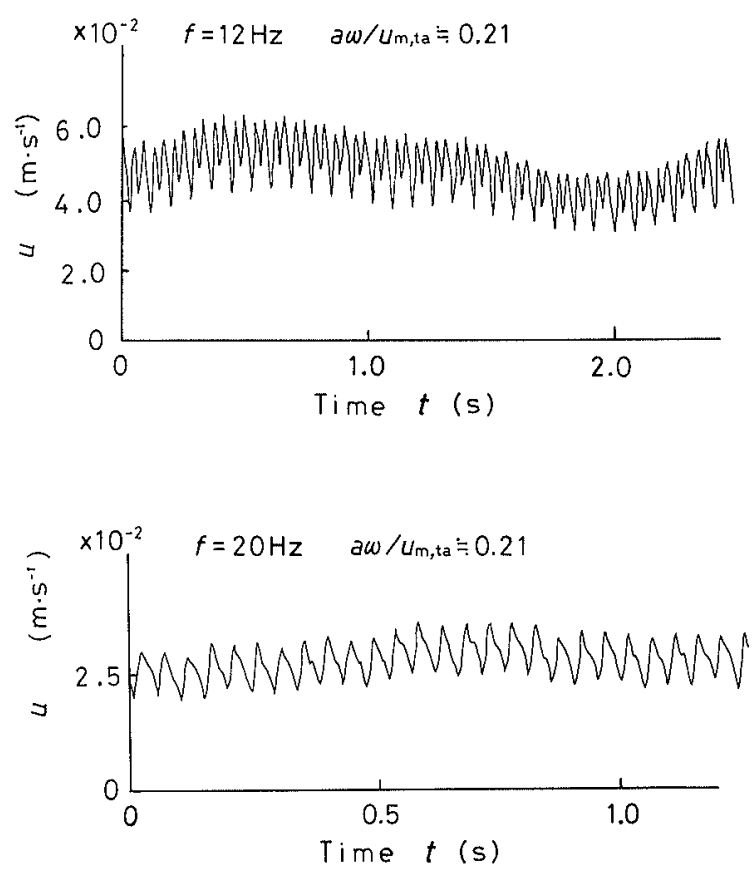

Fig. 7. Velocity waveform in pulsating flow without reverse flow in the case of water model.

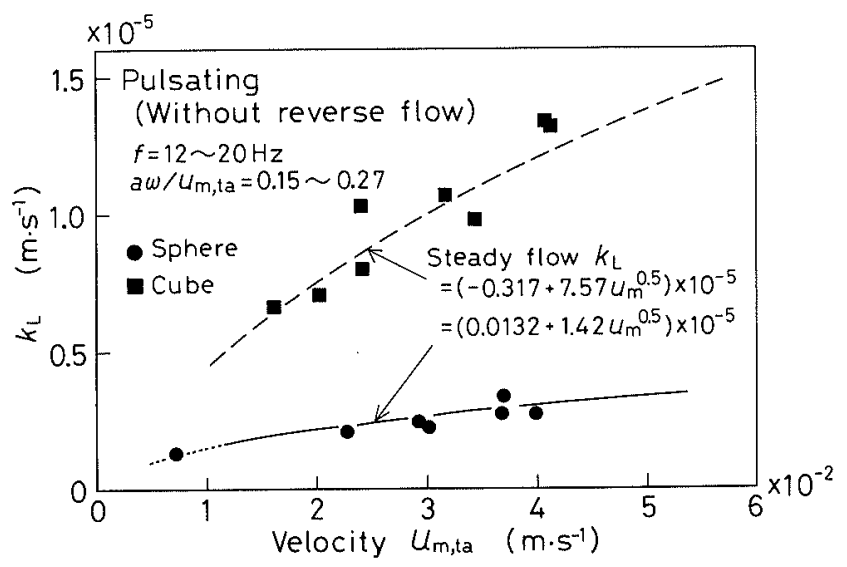

Fig. 8. Comparison between $k_{L}$ in pulsating flow without reverse flow and $k_{L}$ in steady flow (horizontal packed bed).

(i.e., boundary layer became thinner) despite no reverse flow.

According to the report of Gibert and Angelino, ${ }^{7)}$ the pulsation effect index $V$ for a single particle when no reverse flow exists can be represented by

$$
V=\left(4 a f / u_{m, \mathrm{ta}}\right) \cdot[d /(2 a)]^{0.45} .
$$

They insisted that when $V \gtrsim 0.06$, the pulsation effect can be observed. Under the present experimental conditions without reverse flow, $V>0.1$, which indicates that pulsation effect should appear.

However, from Fig. 8, no significant difference can be found between the results of pulsating flow and those of steady flow for both sphere- and cube-packed bed. The reasons may be as follows: In the case of packed bed, the flow phenomenon is different from that in the case of a single particle, even in the present case where Reynolds number $\left(u_{m} \cdot D / v\right)$ based on the inside diameter of pipe $D$ and superficial liquid velocity $u_{m}$ is 2000 or 
less and the main flow is steady flow without turbulence. Because flow channeling or the wake behind particles in the packed bed cause violent mixing and agitation of the liquid, active renewal of the liquid around the surfaces of particles, i.e., active mass transfer may occur. In packed beds, therefore, the effect of reaction rate enhancement like a single sphere by the secondary flow or the vortex in wake under the pulsating flow may no longer appear; consequently, application of pulsation under these experimental conditions to the packed bed may give no effect. Even in pulsating flow without reverse flow, however, if frequency of pulsation is extremely high and velocity amplitude ratio is close to 1 , pulsation effect can be more or less expected from the above-mentioned results of velocity variation measurement.

\subsubsection{In the Case of Pulsating Flow with Reverse Flow $\left(a \omega / u_{m, \mathrm{ta}}>1\right)$}

As to the conditions for the experiments with reverse flow by using the apparatus shown in Fig. 2(b), low frequency $f=1-2 \mathrm{~Hz}$, fluid amplitude $a=8-51 \mathrm{~mm}$ and velocity amplitude ratio $a \omega / u_{m, \text { ta }}=3.8-27.5$ were adopted; such experimental conditions caused pulsating flow with great reverse flow. In this case, too, a series of steady flow experiments were carried out before and after the pulsating flow experiments for the purpose of

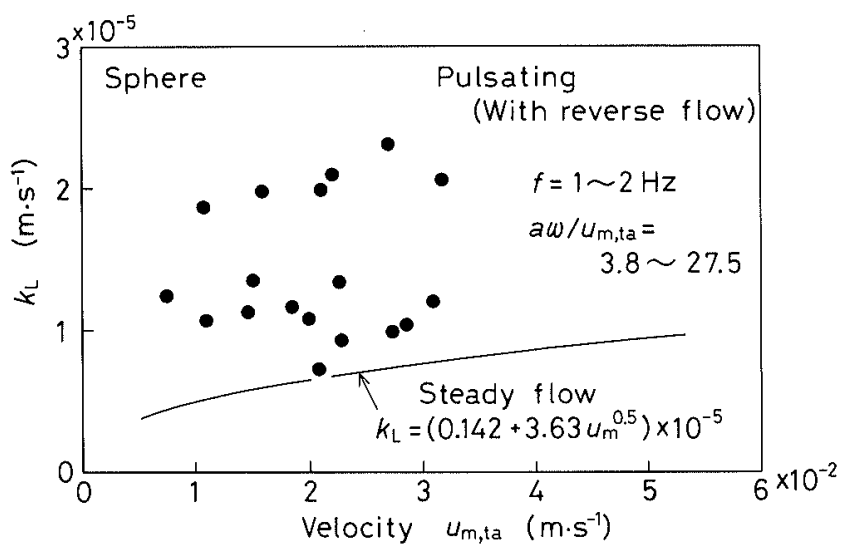

Fig. 9. Comparison between $k_{L}$ in pulsating flow with reverse flow and $k_{L}$ in steady flow (vertical packed bed of spheres).

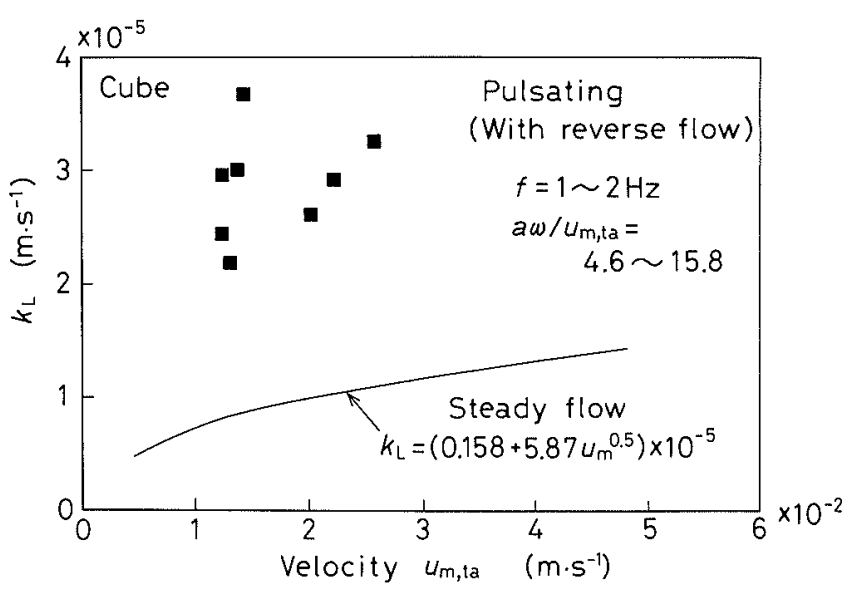

Fig. 10. Comparison between $k_{L}$ in pulsating flow with reverse flow and $k_{L}$ in steady flow (vertical packed bed of cubes). comparison. The experimental results for sphere- and cube-packed bed are shown in Figs. $\mathbf{9}$ and 10, respectively. The solid lines in these figures are the approximate curves for steady flow. It is well understood from these figures that the addition of pulsating flow with reverse flow greatly enhances the mass transfer rate in comparison with that under steady flow.

Now, how much rate enhancement of mass transfer can be obtained under what sort of pulsating flow conditions is discussed: Quasi-steady state analysis is carried out here under the assumptions that the absolute value of velocity contributes to the rate of mass transfer, and that reactions proceed in a quasi-steady state in each instant of pulsation.

From Eqs. (8) and (9), the mass transfer coefficient in steady flow $k_{L, s t}$ can be represented in a general form as

$$
k_{L, \mathrm{st}}=b+c u_{m, \mathrm{st}}^{0.5}
$$

where $b$ and $c$ are constants, and in $u_{m, s t}$ the subscript st indicating steady flow is used for differentiating it from superficial liquid velocity in pulsating flow. In the next place, superficial liquid velocity in pulsating flow $u_{m, \mathrm{pl}}$ is assumed to vary sinusoidally, i.e.

$$
u_{m, \mathrm{pl}}=u_{m, \mathrm{ta}}+a \omega \sin \omega t
$$

Therefore, the mass transfer coefficient $k_{L, \mathrm{pl}}$ in pulsating flow in a quasi-steady state can be written as

$$
k_{L, \mathrm{pl}}=b+c\left|u_{m, \mathrm{ta}}+a \omega \sin \omega t\right|^{0.5} .
$$

Under the assumption of $u_{m, \mathrm{ta}}=u_{m, \mathrm{st}}$, the ratio of the time-averaged mass transfer coefficient in pulsating flow to the mass transfer coefficient in steady flow, $\overline{k_{L, \mathrm{pl}}} / k_{L, \mathrm{st}}$, namely, the ratio of dimensionless mass transfer coefficients, $S h_{\mathrm{pl}} / S h_{\mathrm{st}}$, can be expressed from Eqs. (11) and (13) as follows:

$$
\begin{aligned}
& \frac{S h_{\mathrm{p} 1}}{S h_{\mathrm{st}}}=\frac{b /\left(c u_{m, \mathrm{ta}}^{0.5}\right)}{b /\left(c u_{m, \mathrm{ta}}^{0.5}\right)+1} \\
& +\frac{\{1 /(2 \pi)\} \times \int_{0}^{2 \pi}\left|1+\left(a \omega / u_{m, \mathrm{ta}}\right) \sin \omega t\right|^{0.5} d(\omega t)}{b /\left(c u_{m, \mathrm{ta}}^{0.5}\right)+1} \ldots . .
\end{aligned}
$$

Consequently, $\overline{k_{L, \mathrm{pl}}} / k_{L, \mathrm{st}}$, i.e., ratio of dimensionless mass transfer coefficients $S h_{\mathrm{pl}} / S h_{\mathrm{st}}$ can be represented as functions of velocity amplitude ratio $a \omega / u_{m, \text { ta }}$ and timeaveraged superficial liquid velocity $u_{m, \mathrm{ta}}$.

Therefore, Figs. 9 and 10 are rearanged on the basis of Eq. (14); experimental values of $S h_{\mathrm{pl}} / S h_{\mathrm{st}}$ for spheres and cubes are plotted as a function of $a \omega / u_{m, \text { ta }}$ and with a parameter of $u_{m, \text { ta }}$ in Figs. 11 and 12, respectively. In addition, the quasi-steady approximate curves are also delineated in the two figures at $u_{m, \text { ta }}=0.005,0.01,0.02$, 0.04 and $0.1 \mathrm{~m} / \mathrm{s}$. For spheres, the measured values nearly correspond to the quasi-steady approximate curves within an error of about $25 \%$, and therefore the reaction seems to proceed in a quasi-steady state. For cubes, on the other hand, the measured values lie over the quasi-steady approximate curves, that is, they are always greater than the quasi-steady values. In a system like 


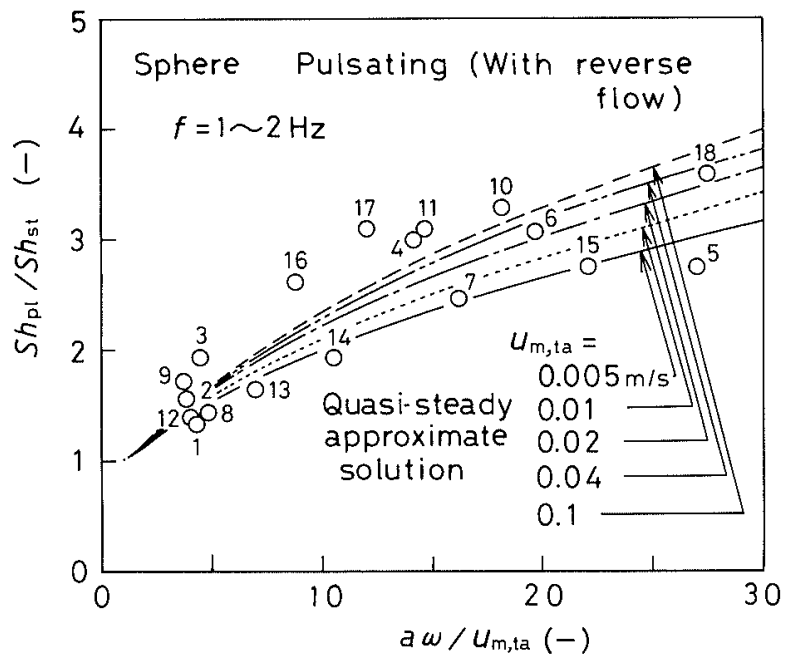

Fig. 11. Comparison between $S h_{p l} / S h_{\mathrm{st}}$ measured and calculated from quasi-steady approximate solution (vertical packed bed of spheres).

\begin{tabular}{cccccccccc}
\hline No. & 1 & 2 & 3 & 4 & 5 & 6 & 7 & 8 & 9 \\
\hline $\begin{array}{c}u_{m, \text { ta }} \\
\times 10^{2}(\mathrm{~m} / \mathrm{s})\end{array}$ & 2.28 & 3.10 & 2.26 & 2.09 & 1.10 & 1.51 & 1.85 & 2.08 & 2.73 \\
\hline No. & 10 & 11 & 12 & 13 & 14 & 15 & 16 & 17 & 18 \\
\hline $\begin{array}{c}u_{m, \mathrm{ta}} \\
\times 10^{2}(\mathrm{~m} / \mathrm{s})\end{array}$ & 1.59 & 2.21 & 2.86 & 2.01 & 1.46 & 0.75 & 3.17 & 2.69 & 1.07 \\
\hline
\end{tabular}

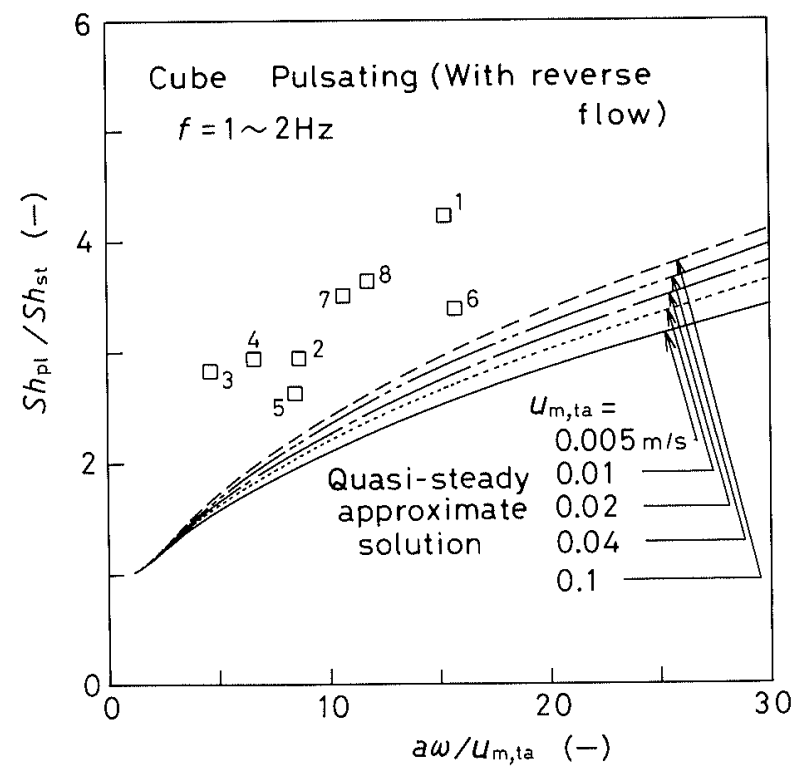

Fig. 12. Comparison between $S h_{p l} / S h_{\mathrm{st}}$ measured and calculated from quasi-steady approximate solution (vertical packed bed of cubes).

\begin{tabular}{ccccccccc}
\hline No. & 1 & 2 & 3 & 4 & 5 & 6 & 7 & 8 \\
\hline $\begin{array}{c}u_{m, \mathrm{ta}} \\
\times 10^{2}(\mathrm{~m} / \mathrm{s})\end{array}$ & 1.44 & 1.25 & 2.24 & 2.58 & 2.04 & 1.40 & 1.38 & 1.26 \\
\hline
\end{tabular}

this where overall reaction is rate-determined by mass transfer, mass transfer during reverse flow occurs actively according to the absolute value of fluid velocity and directly contributes to the reaction, and hence mass transfer is accelerated. In this manner, the present experiments clarify that the addition of the pulsating flow with reverse flow accelerates the mass transfer from sphere-packed bed in the quasi-steady state and the one from cube-packed bed more than that.

\subsection{Effects of Difference in Shapes}

As described in the preceding sections, the mass transfer from the cube-packed bed is faster than that from sphere-packed bed, no matter whether the type of packed bed is horizontal or vertical. In the following paragraphs, the effect of particle shape on mass transfer from packed beds is discussed by placing emphasis on the state of flow.

In steady flow, as shown in Fig. 6, the frequency of velocity fluctuation immediately after the packed bed of cubes is greater than that of spheres. Consequently, energy consumed by variation in the packed bed of cubes is inferred to be greater than that of spheres. In the sphere-packed bed, particles are packed regularly and the voids among particles are relatively uniform, so that the channeling of flow may not be so great as that in the cube-packed bed. In the cube-packed bed, on the other hand, particles are arranged at random, and the packed state is extremely irregular. Accordingly, the voids among cubes are significantly uneven as compared with those among spheres, the channeling of flow becomes much complicated, and the velocity of liquid passing through the cube-packed bed is greater. Moreover, the presence of corners of each cubic particle tends to cause separation of boundary layer and to form wake easily in comparison with spheres, which brings about flow disturbance or turbulence; these are considered to be the reasons why the mass transfer coefficient for cubes becomes greater than that for spheres.

The number of dead water region in the cube-packed bed is larger than that in the sphere-packed bed, and the voids among particles are extremely irregular as mentioned above. When pulsating flow with reverse flow is added to this cube-packed bed, the passing channel of reverse flow often differs from that of fair flow (flow in the positive direction), and during reverse flow, liquid tends to flow into the dead water zones during fair flow. This suggests that the addition of reverse flow increases effective reaction area. Consequently, in the cube-packed bed, mass transfer is considered to be accelerated more than the value estimated by quasi-steady approximate calculation.

\section{Conclusions}

As to liquid-solid reactions in the beds packed with spherical and cubic particles for $\mathrm{Fe}^{3+}$-iron particle system, the mass transfer coefficients for both steady and pulsating flows were measured, and the following conclusions were obtained:

(1) Mass transfer coefficient $k_{L}$ in steady flow can be expressed as follows within the range of the present experiments:

$$
\left.k_{L}=\left(0.142+3.63 u_{m}^{0.5}\right) \times 10^{-5}(\mathrm{~m} / \mathrm{s}) \quad \text { (for sphere }\right)
$$




$$
k_{L}=\left(0.158+5.87 u_{m}^{0.5}\right) \times 10^{-5}(\mathrm{~m} / \mathrm{s}) \quad \text { (for cube) }
$$

and $k_{L}$ for cubes is greater than that for spheres under the same $u_{m}$.

(2) As to the mass transfer coefficients for pulsating flow under the present experimental conditions, no effect of mass transfer enhancement due to pulsation was observed for both spheres and cubes when there was no reverse flow. On the other hand, mass transfer was accelerated when there was reverse flow.

(3) In pulsating flow with reverse flow, it was made clear that in the sphere-packed bed mass transfer rate was enhanced in a quasi-steady state, and that in the cube-packed bed the rate was accelerated more than that.

\section{Acknowledgement}

This study was carried out in close cooperation with Nisshin Steel Co., Ltd. under the Joint Research (B) with Private Sectors etc. in the fiscal years 1988 and 1989.

\section{Nomenclature}

$A$ : total surface area of particles in packed bed $\left(\mathrm{m}^{2}\right)$

$a$ : amplitude of liquid under pulsating flow $(\mathrm{m})$

$C_{b}: \mathrm{Fe}^{3+}$ ion concentration in bulk liquid $\left(\mathrm{kg} / \mathrm{m}^{3}\right)$

$d$ : representative diameter (sphere: $d_{p}$, cube: $d_{p}^{*}$ ) (m)

$d_{p}:$ diameter of sphere $(\mathrm{m})$

$d_{p}^{*}$ : volume equivalent diameter for cube (diameter of a sphere of equal volume to particle) (m)

$f:$ frequency $(\mathrm{Hz})$

$k_{L}:$ mass transfer coefficient $(\mathrm{m} / \mathrm{s})$

$Q:$ flow rate $\left(\mathrm{m}^{3} / \mathrm{s}\right)$

Re: Reynolds number (-)

$S h$ : Sherwood number $(-)$ $u: \quad$ velocity $(\mathrm{m} / \mathrm{s})$

$u_{m}$ : superficial liquid velocity based on empty column $(\mathrm{m} / \mathrm{s})$

$u_{m, \mathrm{ta}}:$ time-averaged superficial liquid velocity $(\mathrm{m} / \mathrm{s})$

$v:$ dynamic viscosity $\left(\mathrm{m}^{2} / \mathrm{s}\right)$

$\omega:$ angular frequency $=2 \pi f(\mathrm{rad} / \mathrm{s})$

\section{REFERENCES}

1) M. Ohmi, T. Usui, Y. Matsumoto and Y. Masuyama: Tetsu-to-Hagané, 64 (1978), 1105; Trans. Iron Steel Inst. Jpn., 22 (1982), 600.

2) Y. Kitaura, H. Tanaka, G. Ueda and N. Kojima: Kagaku Kōgaku, 33 (1969), 175.

3) Y. Mori, M. Imabayashi, K. Hijikata and Y. Yoshida: Int, J. Heat Mass Trans., 12 (1969), 571.

4) S. Taniguchi, M. Ohmi and M. Yamada: Tetsu-to-Hagané, 59 (1973), 1497; Trans. Iron Steel Inst. Jpn., 14 (1974), 241.

5) M. Ohmi and T. Usui: Tetsu-to-Hagané, 59 (1973), 1902; Trans. Iron Steel Inst. Jpn., 16 (1976), 85.

6) K. Takahashi and K. Endoh: J. Chem. Eng. Jpn., 22 (1989), 120.

7) H. Gibert and H. Angelino: Int. J. Heat Mass Trans., 17 (1974), 625.

8) M. Ohmi and T. Usui: Tetsu-to-Hagané, 63 (1977), 1633: Trans. Iron Steel Inst. Jpn., 22 (1982), 593.

9) T. Shirotsuka and N. Honda: Kagaku Kögaku, 21 (1957), 287.

10) T. Shirotsuka, N. Honda and Y. Shima: Kagaku Kōgaku, 21 (1957), 638.

11) M. Ohmi, T. Usui and Y. Kusaba: Tetsu-to-Hagané, 59 (1973), S5.

12) T. Usui, M. Ohmi and H. Todani: Preprint for Meeting of Chem. Eng. Jpn., (Oct. 1982), 568

13) For ex., S. Matsubara,Y. Miwa, K. Takagi, T. Omi and K. Miyanami: Tetsu-to-Hagané, 76 (1990), 751.

14) S. Matsubara, Y. Miwa, K. Takagi, Y. Shirataki, A. Takezoe and T. Omi: Tetsu-to-Hagané, 75 (1989), 2075.

15) W. E. Ranz: Chem. Eng. Prog., 48 (1952), 247.

(Originally published in Tetsu-to-Hagané, 77 (1991), 913, in Japanese) 